\title{
The Sensing Characteristics of a Bragg Fiber Based Plasmonic Biosensor Using an $\mathrm{As}_{2} \mathrm{~S}_{3}$ Chalcogenide Layer
}

\author{
Vasile Popescu $^{1,}$, , Niculae Puscas ${ }^{1}$, Guido Perrone ${ }^{2}$ \\ ${ }^{1}$ Department of Physics, University Politehnica of Bucharest, Bucharest, Romania \\ ${ }^{2}$ Department of Electronics and Telecommunications, Politecnico di Torino, Torino, Italy
}

\section{Email address:}

vapopescu@yahoo.com (V. Popescu)

${ }^{*}$ Corresponding author

\section{To cite this article:}

Vasile Popescu, Niculae Puscas, Guido Perrone. The Sensing Characteristics of a Bragg Fiber Based Plasmonic Biosensor Using an $\mathrm{As}_{2} \mathrm{~S}_{3}$ Chalcogenide Layer. Optics. Vol. 6, No. 2, 2017, pp. 21-27. doi: 10.11648/j.optics.20170602.12

Received: December 7, 2017; Accepted: December 18, 2017; Published: January 10, 2018

\begin{abstract}
The sensing performances of a four layer Bragg fiber based plasmonic biosensor for aqueous solutions using an $\mathrm{As}_{2} \mathrm{~S}_{3}$ chalcogenide layer are investigated with an analytical method. In comparison with a previously considered fiber structure with a GaP layer, the new geometry has the advantages of a smaller value of the full width at half maximum and a larger value of the signal-to-noise ratio; however, the maximum of amplitude sensitivity is smaller when an $\mathrm{As}_{2} \mathrm{~S}_{3}$ layer is used in the place of the GaP layer. If the thickness of the $\mathrm{As}_{2} \mathrm{~S}_{3}$ layer is increased to the value for which it is quarter wavelength, the power fraction carried at the resonant wavelength by the core guided mode in the analyte layer becomes comparable with the value obtained in an optical fiber with the GaP layer, evidencing that the higher value of the refractive index for the GaP layer is compensated by a larger value of the thickness for the $\mathrm{As}_{2} \mathrm{~S}_{3}$ layer. Taking into account the 0.04 photoinduced refractive index change obtained by illumination the chalcogenide $\mathrm{As}_{2} \mathrm{~S}_{3}$ layer with a laser beam, the resonant wavelength is decreased by $0.128 \mathrm{~nm}$ and the loss for the core mode is increased by $41 \mathrm{~dB} / \mathrm{cm}$.
\end{abstract}

Keywords: Sensors, Surface Plasmon Resonance, Chalcogenides, Bragg Fiber, Transfer Matrix Method

\section{Introduction}

The interest for photonic bandgap Bragg fiber-based plasmonic devices has lately had a boost due to the availability of novel fiber types. These structures can be used as chemical and biochemical sensors exploiting either the phase matching [1-2] or the loss matching [3] conditions between the fundamental core mode and a plasmon mode. In recently published papers [4, 6], these devices have been studied by comparing a finite element method with an analytical method in which the radial solutions of the wave equation are represented by a Bessel function of the first kind $(J)$ in the core region, a linear combination of Bessel functions of the first and second kinds $(J$ and $Y$ ) in the dielectric inner clad layers, a linear combination of the Hankel functions $H_{1}$ and $H_{2}$ to represent the field in the gold region just before the outermost sensing region and of modified Bessel function of the second kind $(K)$ in the outermost region. In particular, this analytical approach was used to analyze these sensing performance of a Bragg fiber-based plasmonic sensor with four layers $\left(\mathrm{SiO}_{2}, \mathrm{GaP}\right.$, gold, and $\left.\mathrm{H}_{2} \mathrm{O}\right)$, which has been used both when the analyte is an aqueous solution [6] and a liver tissue [7].

This paper analyzes the performance of a four-layer sensor similar to that described in [6], but in which the GaP layer is substituted by an $\mathrm{As}_{2} \mathrm{~S}_{3}$ film. This opens new sensing possibilities as it has been demonstrated that it is possible to obtain a photoinduced change of the refractive index of a chalcogenide $\mathrm{As}_{2} \mathrm{~S}_{3}$ sample by illuminating with a green laser beam [8]. In the cited reference, a photoinduced change of $\Delta n=+0.01$ or $\Delta n=+0.04$ has been achieved over the visible and infrared wavelength regions, using pulsed lasers emitting at $\lambda=514.5 \mathrm{~nm}$ with an intensity $I=10 \mathrm{mWmm}^{-2}$. In this work we use the previously mentioned analytical method to determine the characteristics of a Bragg fiber-based plasmonic sensor using an $\mathrm{As}_{2} \mathrm{~S}_{3}$ chalcogenide layer, taking into account a photoinduced increase of the refractive index of the $\mathrm{As}_{2} \mathrm{~S}_{3}$ layer by proper illumination with a laser beam. 


\section{The Bragg Plasmonic Optical Fiber with a Chalcogenide Layer}

The considered photonic bandgap Bragg optical fiberbased plasmonic sensor (Figure 1) is made by a $\mathrm{SiO}_{2}$ core in the center of the structure, surrounded by an inner $\mathrm{As}_{2} \mathrm{~S}_{3}$ layer, a gold reflector layer and a water-based analyte layer.

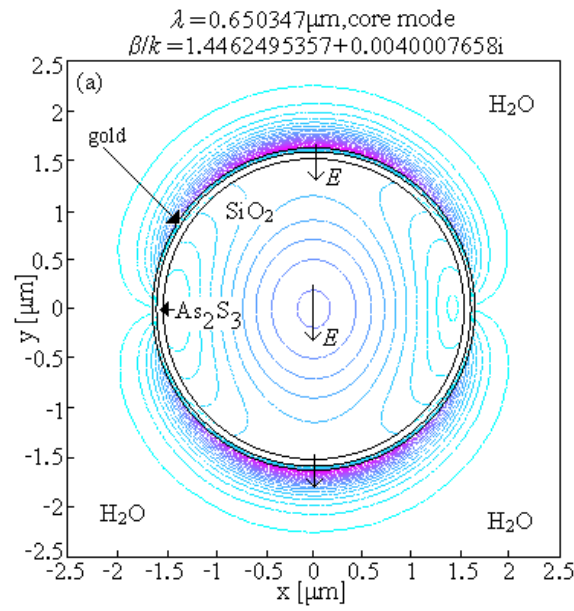

The structure is similar to that in reference [6], except for the substitution of the stronger reflector GaP layer with the $\mathrm{As}_{2} \mathrm{~S}_{3}$ layer, a choice that lowers the modal confinement in the fiber core at the resonant wavelength, but increases the power fraction carried by the core guided mode in the analyte and in the gold layers.

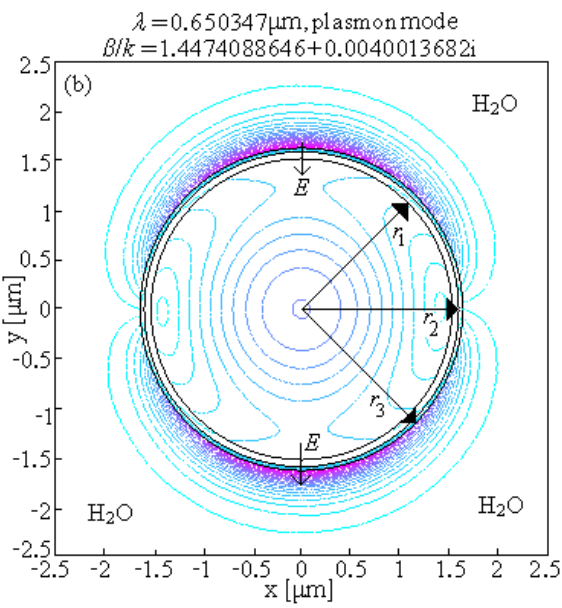

Figure 1. Contour plot of the electric field at the loss matching point $(\lambda=0.650347 \mu m)$ for the guided (a) and plasmon (b) modes when the analyte is distilled water for a fiber with $r_{1}=1.527 \mu \mathrm{m}, r_{2}=1.597 \mu \mathrm{m}, r_{3}=1.637 \mu \mathrm{m}, d_{1}=40 \mathrm{~nm}, d_{2}=70 \mathrm{~nm}$. The arrows represent the direction of the main electric field E.

In the following simulations the refractive index of silica [9-11], distilled water [12] and $\mathrm{As}_{2} \mathrm{~S}_{3}$ [13] materials are calculated through a Sellmeier relation, whereas that of the gold layer is determined with a Drude formula $[9-10,14]$.

\section{Results and Discussion}

For a device made of a $\mathrm{SiO}_{2}$ core $\left(r_{1}=1.527 \mu \mathrm{m}\right)$ surrounded by an $\mathrm{As}_{2} \mathrm{~S}_{3}$ layer (thickness $d_{2}=r_{2}-\mathrm{r}_{1}=40 \mathrm{~nm}$ ), a gold layer (thickness $d_{1}=r_{3}-\mathrm{r}_{2}=40 \mathrm{~nm}$ ), and distilled water analyte layer, the loss matching point is at $\lambda=$ $0.614036 \mu \mathrm{m}$ when is calculated with the analytical method. At this resonant wavelength where the value of refractive index of the $\mathrm{As}_{2} \mathrm{~S}_{3}$ chalcogenide layer is $n_{\mathrm{c}}=2.622547$, the effective index $\beta / k$ for the core and plasmon modes are $1.4504031+0.0035888 \mathrm{i}$ and $1.4508409+0.0035921 \mathrm{i}$, respectively. The difference $\Delta(\beta / k)_{\mathrm{i}}$ between the imaginary parts of their effective indices is $\Delta(\beta / k)_{\mathrm{i}}=3.3 \times 10^{-6}$. For another resonant wavelength, $\lambda=0.6140367 \mu \mathrm{m}$ (very close to the previous one) and $n_{\mathrm{c}}=2.622546$, the effective index $\beta / k$ for the core and plasmon modes become $1.4508409817+$ $0.0035903265 \mathrm{i}$ and $1.4504026570+0.0035905515 \mathrm{i}$, respectively. In this case the difference $\Delta(\beta / k)_{\mathrm{i}}$ between the imaginary parts of the effective indices is $\Delta(\beta / k)_{\mathrm{i}}=2.3 \times 10^{-7}$. At the two resonant wavelengths $(\lambda=0.614036 \mu \mathrm{m}$ and $\lambda=$ $0.6140367 \mu \mathrm{m})$, the core and plasmon modes are inverted at the loss matching points.

Figures $1 \mathrm{a}$ and $1 \mathrm{~b}$ show the contour plot of the electric field at the loss matching point $(\lambda=0.650347 \mu \mathrm{m})$ for the guided $H E_{11}$ and plasmon modes when the analyte is distilled water for a fiber with $r_{1}=1.527 \mu \mathrm{m}, r_{2}=1.597 \mu \mathrm{m}, r_{3}=$ $1.637 \mu \mathrm{m}, d_{1}=40 \mathrm{~nm}, d_{2}=70 \mathrm{~nm}$. At the resonant wavelength $\left(\lambda=0.650347 \mu \mathrm{m}, n_{\mathrm{c}}=2.592692\right)$, the effective index $\beta / k$ for the core and plasmon modes are $1.4462495357+$ $0.0040007658 \mathrm{i}$ and $1.4474088646+0.0040013682 \mathrm{i}$, respectively. The difference $\Delta(\beta / k)_{\mathrm{i}}$ between the imaginary parts of the effective indices of the core and plasmon modes is $\Delta(\beta / k)_{\mathrm{i}}=6.0 \times 10^{-7}$. The thickness $d_{2}=70 \mathrm{~nm}$ of the chalcogenide layer is determined by using the quarter wave condition $\lambda=4 d_{2} \sqrt{n_{c}^{2}-n_{1}^{2}} \approx 4 d_{2} \sqrt{n_{c}^{2}-(\beta / k)_{\text {core }}^{2}}$ where $n_{1}$ and $n_{\mathrm{c}}$ are the refractive indices of the $\mathrm{SiO}_{2}$ and $\mathrm{As}_{2} \mathrm{~S}_{3}$ layers at $\lambda=0.614036 \mu \mathrm{m}$, respectively. Similarly, the thickness $d_{1}$ $=40 \mathrm{~nm}$ of the gold layer is determined by using the quarter wave condition $\lambda=4 d_{1} \sqrt{n_{g}^{2}-n_{1}^{2}} \approx 4 d_{1} \sqrt{n_{g}^{2}-(\beta / k)_{\text {core }}^{2}}$ where $n_{\mathrm{g}}$ is the refractive index of the gold layer at the same initial wavelength $\lambda=0.614036 \mu \mathrm{m}$.

Figures $2 \mathrm{a}$ and $2 \mathrm{~b}$ show the contour plot of the electric field at non-resonant wavelength $\lambda=0.614036 \mu \mathrm{m}(\lambda=$ $0.62909 \mu \mathrm{m})$ for the guided modes when the thickness $d_{1}=$ $40 \mathrm{~nm}$ and $d_{2}=70 \mathrm{~nm}$ of the gold and $\mathrm{As}_{2} \mathrm{~S}_{3}$ layers $\left(d_{1}=41 \mathrm{~nm}\right.$ and $d_{2}=52 \mathrm{~nm}$ of the gold and GaP layers) are determined by using the quarter wave condition. The effective index $\beta / k$ for the core and plasmon modes are $1.4486213662+$ $0.0004711290 \mathrm{i}$ and $1.4628612147+0.0085131443 \mathrm{i}$ at $\lambda=$ $0.614036 \mu \mathrm{m} \quad(1.4474933498+0.0013643282 \mathrm{i}$ and $1.4550957049+0.0066673325 \mathrm{i}$ at $\lambda=0.62909 \mu \mathrm{m})$, respectively. In these fibers, the optical confinement for the $\mathrm{HE}_{11}$ mode in the core is very large in comparison with that for a structure with a resonant condition between the core and plasmon modes. Thus, the power fraction carried in $\mathrm{SiO}_{2}$ layer is 0.944123 for a fiber with an $\mathrm{As}_{2} \mathrm{~S}_{3}$ layer and 0.849012 for a fiber with a GaP layer (Table 1). 

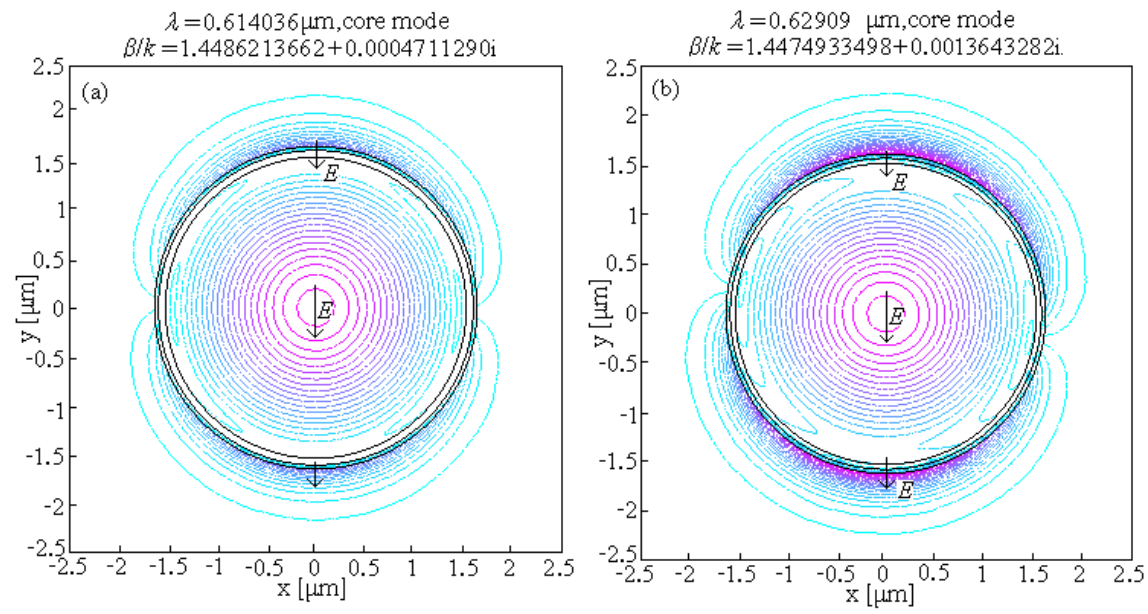

Figure 2. Contour plot of the electric field at non-resonant wavelengths $\lambda=0.614036 \mu \mathrm{m}$ (a) and $\lambda=0.62909 \mu \mathrm{m}$ (b) for the guided modes when the thickness $d_{1}=40 \mathrm{~nm}$ and $d_{2}=70 \mathrm{~nm}$ of the gold and $A s_{2} S_{3}$ layers (a) and $d_{1}=41 \mathrm{~nm}$ and $d_{2}=52 \mathrm{~nm}$ of the gold and GaP layers (b) are determined by using the quarter wave condition. The arrows represent the direction of the main electric field $E$.

Figure 3 and Figure 4 show, respectively, the real part and the imaginary part (together with the loss spectra) of the effective index versus wavelength for the core and plasmon modes near the loss matching point $(\lambda=0.614036 \mu \mathrm{m})$. It is interesting to note that at this wavelength, the power fractions (Table 1) carried by the core guided mode in the analyte $(0.390454)$ and in gold $(0.008056)$ layers are larger than the corresponding values computed for a similar optical fiber with a GaP layer in the place of chalcogenide layer (from [6],

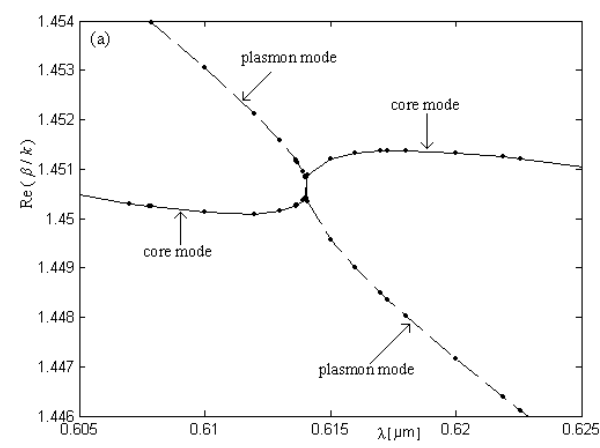

0.363771 in the analyte layer and 0.006814 in the gold layer, $\lambda=0.62909 \mu \mathrm{m})$. This is due to the smaller value of the refractive index of the $\mathrm{As}_{2} \mathrm{~S}_{3}$ layer in comparison with that for the GaP layer. Similarly, the loss $\alpha=3189.7 \mathrm{~dB} / \mathrm{cm}$ for the core mode is larger when an $\mathrm{As}_{2} \mathrm{~S}_{3}$ layer is used in the place of the GaP layer $(\alpha=3091.0 \mathrm{~dB} / \mathrm{cm})$. The loss for the same mode is further increased by $100.1 \mathrm{~dB} / \mathrm{cm}$, to $\alpha=$ $3191.1 \mathrm{~dB} / \mathrm{cm}$, for the other very close resonant wavelength at $\lambda=0.6140367 \mu \mathrm{m}$.

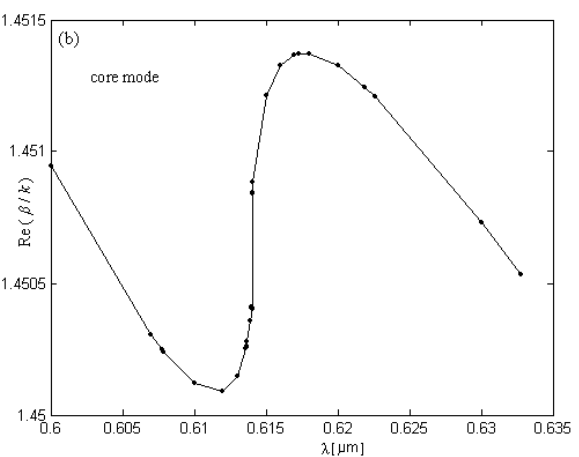

Figure 3. (a) The real part of the effective index versus wavelength for the core and plasmon modes near the loss matching point $(\lambda=0.614036 \mu m)$ for a fiber with $r_{1}=1.527 \mu \mathrm{m}, r_{2}=1.567 \mu \mathrm{m}, r_{3}=1.607 \mu \mathrm{m}, d_{1}=40 \mathrm{~nm}, d_{2}=40 \mathrm{~nm}$. (b) A detail for the core mode.
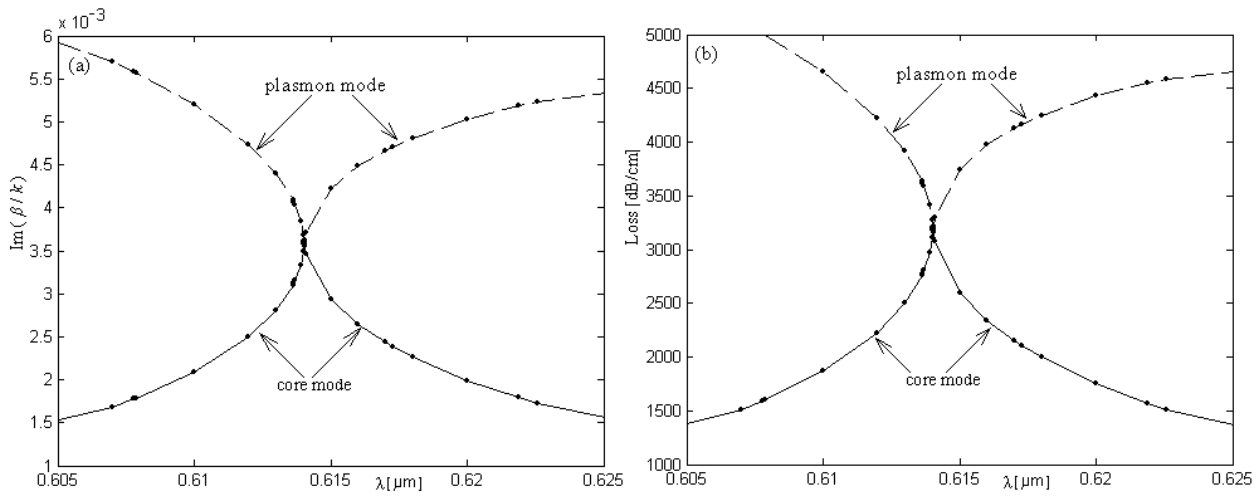

Figure 4. The imaginary part (a) of the effective index for the core and plasmon modes versus wavelength and the loss spectra (b) near the loss matching point for a fiber with $r_{1}=1.527 \mu \mathrm{m}, r_{2}=1.567 \mu \mathrm{m}, r_{3}=1.607 \mu \mathrm{m}, d_{1}=40 \mathrm{~nm}, d_{2}=40 \mathrm{~nm}$. 
As for the fiber with $d_{2}=70 \mathrm{~nm}$, the power fraction (Table 1) carried at the resonant wavelength $(\lambda=0.650347 \mu \mathrm{m})$ by the core guided mode in the analyte (0.363669) and in $\mathrm{SiO}_{2}$ (0.624579) layers is comparable with that for an optical fiber with a $40 \mathrm{~nm} \mathrm{GaP}$ layer $(0.363771$ in the analyte layer and 0.626435 in the $\mathrm{SiO}_{2}$ layer $)$ at its resonance $(\lambda=0.62909 \mu \mathrm{m})$.

Therefore, the higher value of the refractive index for the GaP layer is compensated by a larger value of the thickness $d_{2}$ for the $\mathrm{As}_{2} \mathrm{~S}_{3}$ layer. In these fibers, the optical confinement for the $\mathrm{HE}_{11}$ mode in the core is increased in comparison with that for a structure with an $\mathrm{As}_{2} \mathrm{~S}_{3}$ layer $\left(d_{1}=40 \mathrm{~nm}, d_{2}=\right.$ $40 \mathrm{~nm}, \lambda=0.614036 \mu \mathrm{m})$ where the power fraction carried in $\mathrm{SiO}_{2}$ layer is only 0.595809 .

For a fiber with the loss matching point $\lambda=$ $0.614036 \mu \mathrm{m}$, when an $\mathrm{As}_{2} \mathrm{~S}_{3}$ layer is used in the place of the GaP layer, the resonance spectral width $\delta \lambda_{0.5}$ is decreased

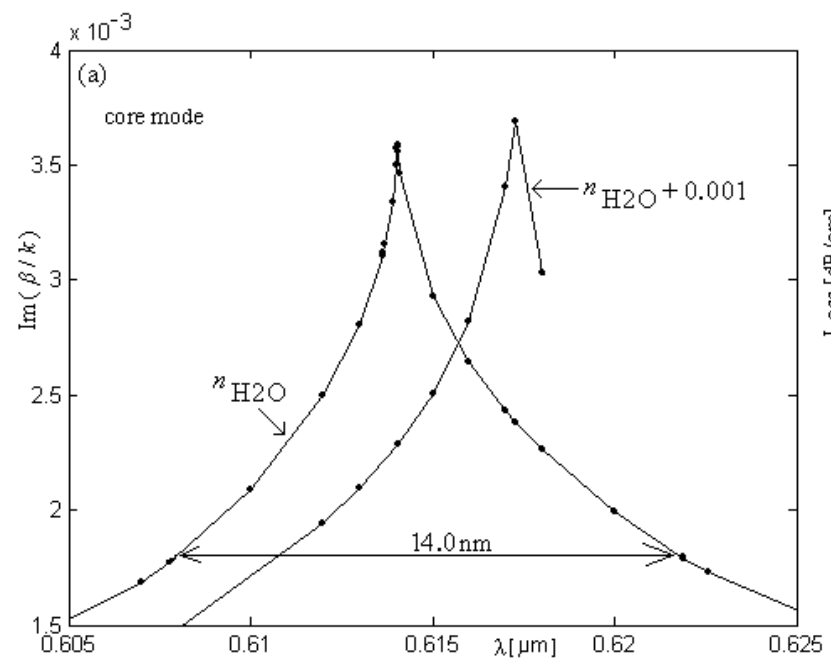

from $19.4 \mathrm{~nm}$ to $14.0 \mathrm{~nm}$. Also, the shift $\delta \lambda_{\text {res }}$ towards longer wavelengths of the loss matching point for an increase $\Delta n_{a}$ of the analyte refractive index by $0.001 \mathrm{RIU}$, from $n_{\mathrm{a}}$ to $n_{\mathrm{a}}+0.001$ (Figure. 5), is increased from $3.2 \mathrm{~nm}$ to $3.3 \mathrm{~nm}$. Figure 6 shows the loss spectra for the core and plasmon modes and the loss spectra of the core mode for two analyte refractive index values $\left(n_{\mathrm{a}}\right.$ and $\left.n_{\mathrm{a}}+0.001\right)$ near the loss matching point $(\lambda=0.650347 \mu \mathrm{m})$ for a fiber with $r_{1}=$ $1.527 \mu \mathrm{m}, r_{2}=1.597 \mu \mathrm{m}, r_{3}=1.637 \mu \mathrm{m}, d_{1}=40 \mathrm{~nm}, d_{2}=70 \mathrm{~nm}$ where $\delta \lambda_{\text {res }}=3.3 \mathrm{~nm}$ and $\delta \lambda_{0.5}=16.4 \mathrm{~nm}$. The maximum value of the amplitude sensitivity $\mathrm{S}_{\mathrm{A}}$ for the guided mode (Figure. 7) is decreased from $3708.8 \mathrm{RIU}^{-1}$ for a fiber with a $\mathrm{GaP}$ layer $(\lambda=0.62909 \mu \mathrm{m})$ to $397.9 \mathrm{RIU}^{-1}$ for $\lambda=$ $0.614036 \mu \mathrm{m}$ and $427.6 \mathrm{RIU}^{-1}$ for $\lambda=0.650347 \mu \mathrm{m}$ for the fibers with $\mathrm{As}_{2} \mathrm{~S}_{3}$ layers.

Figure 5. The imaginary part (a) of the effective index for the core mode versus wavelength and the loss spectra (b) near the loss matching point for two analyte refractive index values $\left(n_{a}\right.$ and $\left.n_{a}+0.001\right)$ for a fiber with $r_{1}=1.527 \mu \mathrm{m}, r_{2}=1.567 \mu \mathrm{m}, r_{3}=1.607 \mu \mathrm{m}, d_{1}=40 \mathrm{~nm}, d_{2}=40 \mathrm{~nm}$.
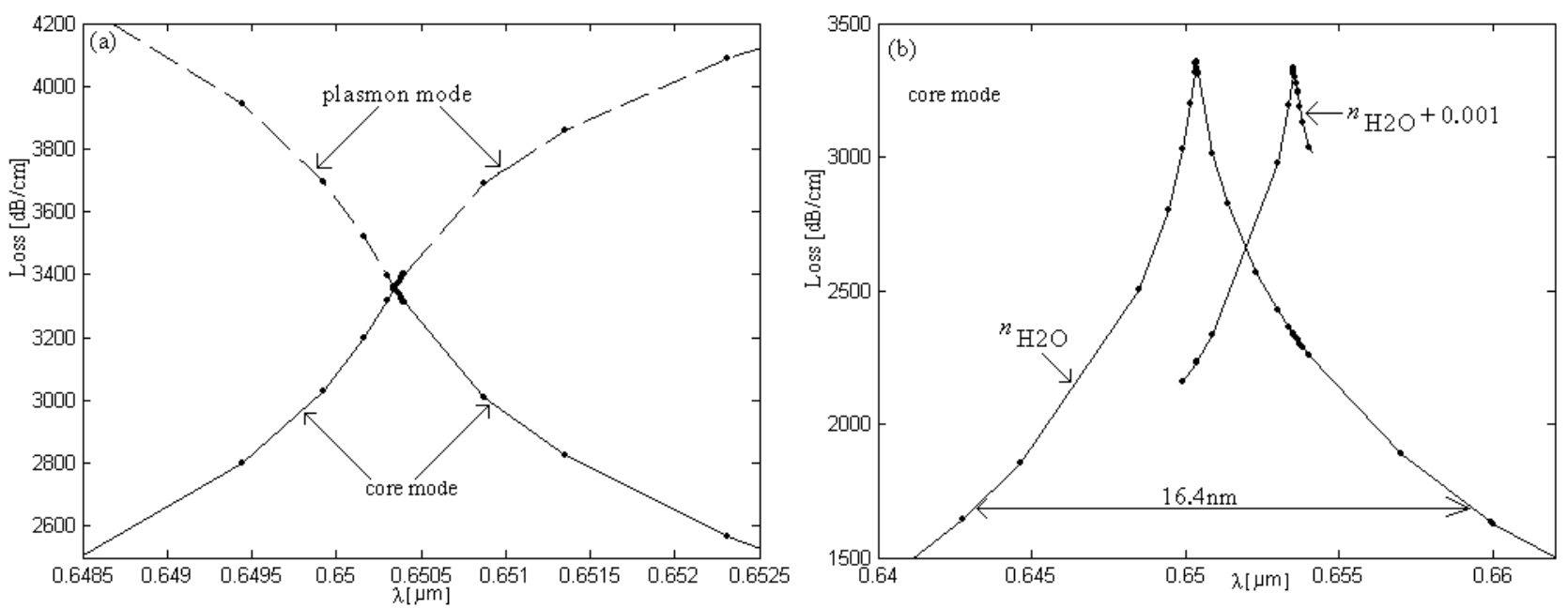

Figure 6. The loss spectra (a) for the core and plasmon modes and the loss spectra of the core mode (b) for two analyte refractive index values ( $n_{a}$ and $n_{a}+$ 0.001) near the loss matching point for a fiber with $r_{1}=1.527 \mu \mathrm{m}, r_{2}=1.597 \mu \mathrm{m}, r_{3}=1.637 \mu \mathrm{m}, d_{1}=40 \mathrm{~nm}, d_{2}=70 \mathrm{~nm}$. 

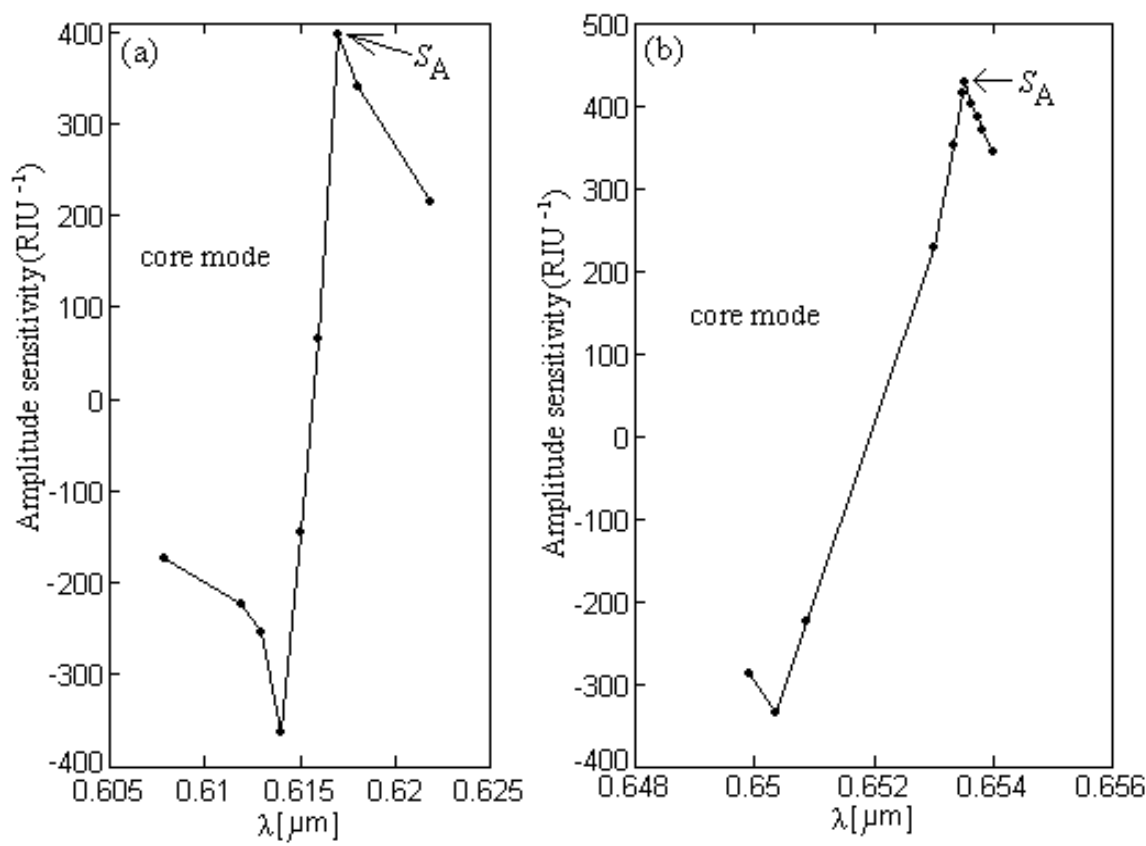

Figure 7. The amplitude sensitivity for the guided mode versus wavelength near the loss matching point with the maximum for $S_{A}=397.9$ RIU ${ }^{1}$ when $d_{2}=$ $40 \mathrm{~nm}(\mathrm{a})$ and $S_{A}=427.6$ RIU ${ }^{1}$ when $d_{2}=70 \mathrm{~nm}(\mathrm{~b})$.

For a photonic bandgap Bragg optical fiber-based surface plasmon resonance sensor with an $\mathrm{As}_{2} \mathrm{~S}_{3}$ layer ( $\mathrm{GaP}$ [6]) layer (Table 2), the shift $\delta \lambda_{\text {res }}$ towards longer wavelengths of the loss matching point for an increase $\Delta n_{a}$ of the analyte refractive index by 0.001 RIU is $3.3 \mathrm{~nm}(3.2 \mathrm{~nm})$, the resonance spectral width $\delta \lambda_{0.5}$ is $14.0 \mathrm{~nm}$ (19.4), the signalto-noise ratio $S N R$ is $0.23(0.17)$, the spectral sensitivity $S_{\lambda}$ is $3264 \mathrm{nmRIU}^{-1}\left(3236 \mathrm{nmRIU}^{-1}\right)$, the spectral resolution $S R_{\lambda}$ is $3.1 \times 10^{-5} \mathrm{RIU}\left(3.1 \times 10^{-5} \mathrm{RIU}\right)$, the amplitude sensitivity $S_{A}$ is $397.9 \mathrm{RIU}^{-1}\left(3708.8 \mathrm{RIU}^{-1}\right)$, the sensor resolution $S R_{A}$ is $2.5 \times 10^{-5} \mathrm{RIU}\left(2.7 \times 10^{-6} \mathrm{RIU}\right)$, the loss $\alpha$ is $3189.7 \mathrm{~dB} / \mathrm{cm}$ $(3091.0 \mathrm{~dB} / \mathrm{cm})$, the propagation length $L$ is $13.6 \mu \mathrm{m}$ $(14.1 \mu \mathrm{m})$, the wavelength $\lambda$ corresponding to the loss matching point is $0.614036 \mu \mathrm{m}(0.62909 \mu \mathrm{m})$, the difference $\Delta \lambda$ between maximal amplitude sensitivity and resonant wavelengths is $3.0 \mathrm{~nm}(2.1 \mathrm{~nm})$, the power fraction $P$ for the core mode in $\mathrm{H}_{2} \mathrm{O}$ is $0.390454(0.363771)$ and the figure of merit FOM [15] is 233.1 (166.8). The sensing parameters for another fiber (Table 2) with an $\mathrm{As}_{2} \mathrm{~S}_{3}$ layer $\left(d_{1}=40 \mathrm{~nm}\right.$ and $d_{2}$ $=70 \mathrm{~nm})$ are characterized by $\delta \lambda_{\text {res }}=3.3 \mathrm{~nm}, \delta \lambda_{0.5}=$ $16.4 \mathrm{~nm}, S N R=0.19, S_{\lambda}=3182 \mathrm{nmRIU}^{-1}, S R_{\lambda}=3.1 \times 10^{-}$ ${ }^{5} \mathrm{RIU}, \quad S_{A}=427.6 \mathrm{RIU}^{-1}, S R_{A}=2.3 \times 10^{-5} \mathrm{RIU}, \quad \alpha=$ $3357.3 \mathrm{~dB} / \mathrm{cm}, L=12.9 \mu \mathrm{m}, \lambda=0.650347 \mu \mathrm{m}, \Delta \lambda=3.2 \mathrm{~nm}, P$ $=0.363669$ and $F O M=192.6$.

Table 1. Power fraction carried in the distilled water, gold, $\mathrm{As}_{2} \mathrm{~S}_{3}(\mathrm{GaP})$ and $\mathrm{SiO}_{2}$ layers of the core guided modes at non-resonant wavelengths $(\lambda=$ $0.614036 \mu \mathrm{m}$ for $d_{1}=40 \mathrm{~nm}, d_{2}=70 \mathrm{~nm}$ and $\lambda=0.62909 \mu \mathrm{m}$ for $\left.d_{1}=41 \mathrm{~nm}, d_{2}=52 \mathrm{~nm}\right)$ and at the loss matching points $\left(\lambda=0.614036 \mu \mathrm{m}\right.$ for $d_{1}=40 \mathrm{~nm}, d_{2}=$ $40 \mathrm{~nm}, \lambda=0.650347 \mu \mathrm{m}$ for $d_{1}=40 \mathrm{~nm}, d_{2}=70 \mathrm{~nm}$ and $\lambda=0.62909 \mu \mathrm{m}$ for $\left.d_{1}=40 \mathrm{~nm}, d_{2}=40 \mathrm{~nm}\right)$.

\begin{tabular}{lllll}
\hline $\boldsymbol{d}_{\mathbf{1}}[\mathbf{n m}] ; \boldsymbol{d}_{\mathbf{2}}[\mathbf{n m}]$ & $\mathbf{H}_{\mathbf{2}} \mathbf{O}$ & $\mathbf{G o l d}$ & $\mathbf{A s}_{\mathbf{2}} \mathbf{S}_{\mathbf{3}}(\mathbf{G a P})$ & $\mathbf{S i O}_{\mathbf{2}}$ \\
\hline $40 ; 70$ & 0.053244 & 0.001101 & 0.001531 & 0.944123 \\
$41 ; 52$ & 0.146871 & 0.002743 & $(0.001374)$ & 0.849012 \\
$40 ; 40$ & 0.390454 & 0.008056 & 0.005681 & 0.595809 \\
$40 ; 70$ & 0.363669 & 0.005545 & 0.006206 & 0.62909 \\
$40 ; 40$ & 0.363771 & 0.006814 & $(0.002980)$ & 0.614036 \\
\hline
\end{tabular}

Table 2. Values of $\delta \lambda_{\text {res }}[\mathrm{nm}], \delta \lambda_{0.5}[\mathrm{~nm}], S N R, F O M\left[R I U^{-1}\right], S_{\lambda}\left[\mathrm{nmRIU}{ }^{-1}\right], S R_{\lambda}[R I U], S_{A}\left[R I U^{-1}\right], S R_{A}[R I U], \alpha[d B / \mathrm{cm}], L[\mu m], \lambda[\mu m], \Delta \lambda[\mathrm{nm}]$ and $P$ for optical fibers with four layers.

\begin{tabular}{|c|c|c|c|c|c|c|}
\hline $\begin{array}{l}\delta \lambda_{\text {res }} \\
\delta \lambda_{0.5}\end{array}$ & $\begin{array}{l}\text { SNR } \\
\text { FOM }\end{array}$ & $\begin{array}{c}S_{\lambda} \\
S R_{\lambda}\end{array}$ & $\begin{array}{l}S_{A} \\
S R_{A}\end{array}$ & $\begin{array}{c}\alpha \\
L\end{array}$ & $\boldsymbol{P}$ & $\begin{array}{l}\lambda \\
\Delta \lambda\end{array}$ \\
\hline $\begin{array}{l}3.3 \\
14.0 \\
3.2 \\
16.4 \\
3.2 \\
19.4 \\
\end{array}$ & $\begin{array}{l}0.23 \\
233.1 \\
0.19 \\
192.6 \\
0.17 \\
166.8 \\
\end{array}$ & $\begin{array}{l}3264 \\
3.1 \times 10^{-5} \\
3182 \\
3.1 \times 10^{-5} \\
3236 \\
3.1 \times 10^{-5}\end{array}$ & $\begin{array}{l}397.9 \\
2.5 \times 10^{-5} \\
427.6 \\
2.3 \times 10^{-5} \\
3708.8 \\
2.7 \times 10^{-6}\end{array}$ & $\begin{array}{l}3189.7 \\
13.6 \\
3357.3 \\
12.9 \\
3091.0 \\
14.1 \\
\end{array}$ & 0.363771 & $\begin{array}{l}0.614036 \\
3.0 \\
0.650347 \\
3.2 \\
0.62909[6] \\
2.1\end{array}$ \\
\hline
\end{tabular}



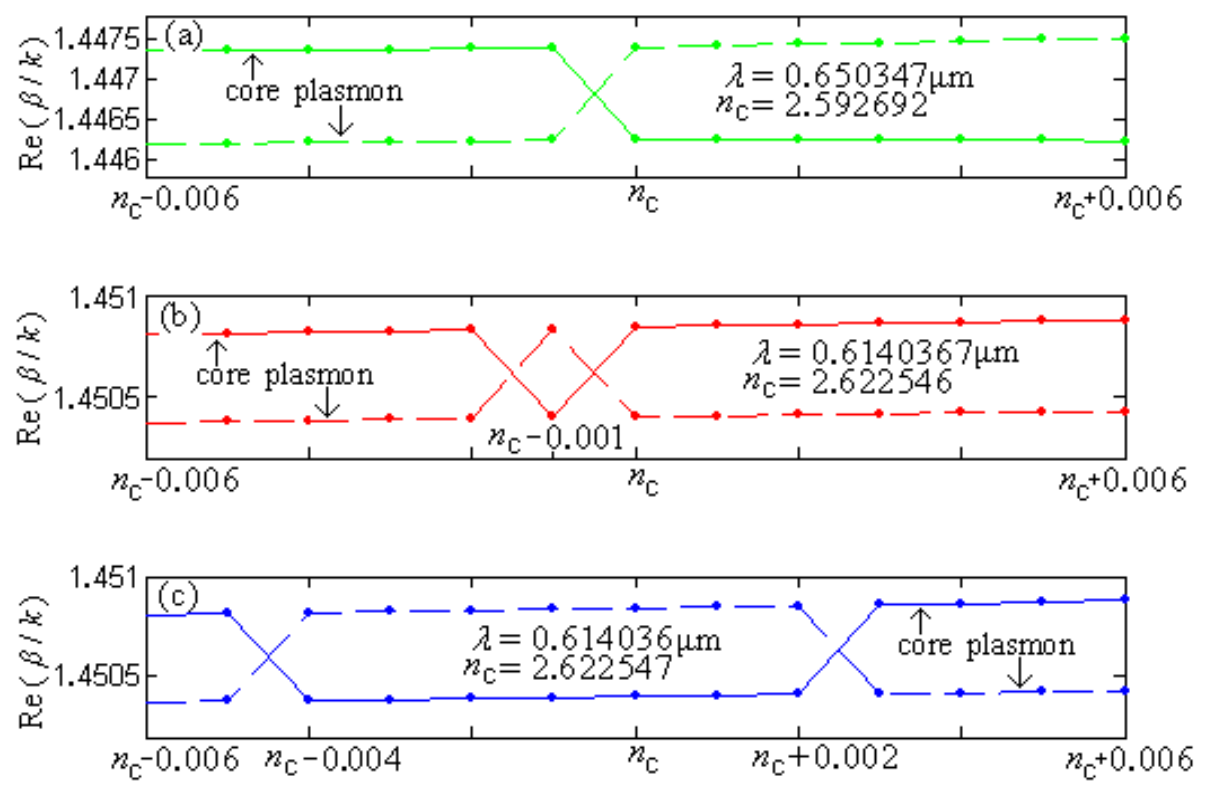

Figure 8. The real part of the effective index versus variation of chalcogenide refractive index for the core and plasmon modes near the loss matching point ( $\lambda$ $=0.650347 \mu \mathrm{m}$ for $d_{2}=70 \mathrm{~nm}(\mathrm{a}), \lambda=0.6140367 \mu \mathrm{m}$ for $d_{2}=40 \mathrm{~nm}$ (b) and $\lambda=0.614036 \mu \mathrm{m} \mathrm{for} d_{2}=40 \mathrm{~nm}(\mathrm{c})$ ).

Figure 8 show the real part of the effective index versus variation of chalcogenide refractive index for the core and plasmon modes near the loss matching point $(\lambda=$ $0.650347 \mu \mathrm{m}$ for $d_{2}=70 \mathrm{~nm}, \lambda=0.6140367 \mu \mathrm{m}$ for $d_{2}=40 \mathrm{~nm}$ and $\lambda=0.614036 \mu \mathrm{m}$ for $d_{2}=40 \mathrm{~nm}$ ). Figure 9 show the loss versus variation of chalcogenide refractive index for the core and plasmon modes near the same loss matching points. At the resonant wavelength $(\lambda=0.614036 \mu \mathrm{m})$, the difference $\Delta$ $(\beta / k)_{\mathrm{i}}$ between the imaginary parts of the effective indices of the core and plasmon modes is $\Delta(\beta / k)_{\mathrm{i}}=3.3 \times 10^{-6}$ for the refractive index $n_{\mathrm{c}}=2.622547$ of the $\mathrm{As}_{2} \mathrm{~S}_{3}$ chalcogenide layer. At the same loss matching point, a smaller difference of $\Delta(\beta / k)_{\mathrm{i}}$ can be obtained at different values of $n_{\mathrm{c}}\left(\Delta(\beta / k)_{\mathrm{i}}=\right.$ $7.9 \times 10^{-7}$ for $n_{\mathrm{c}}-0.004$ and $\Delta(\beta / k)_{\mathrm{i}}=6.6 \times 10^{-7}$ for $\left.n_{\mathrm{c}}+0.002\right)$. The corresponding differences between the losses are $\Delta \alpha=$ $2.9 \mathrm{~dB} / \mathrm{cm}$ for $n_{\mathrm{c}}, \Delta \alpha=0.7 \mathrm{~dB} / \mathrm{cm}$ for $n_{\mathrm{c}}-0.004$ and $\Delta \alpha=$ $0.6 \mathrm{~dB} / \mathrm{cm}$ for $n_{\mathrm{c}}+0.002$. At the resonant wavelength $(\lambda=$ $0.6140367 \mu \mathrm{m}), \Delta(\beta / k)_{\mathrm{i}}=2.3 \times 10^{-7}$ for $n_{\mathrm{c}}=2.622546$. At the same loss matching point, a smaller difference of $\Delta(\beta / k)_{\mathrm{i}}=$ $1.1 \times 10^{-7}$ can be obtained for $n_{\mathrm{c}}-0.001$. At the resonant wavelength $(\lambda=0.650347 \mu \mathrm{m}), \Delta(\beta / k)_{\mathrm{i}}=6.0 \times 10^{-7}$ for the refractive index $n_{\mathrm{c}}=2.592692$.
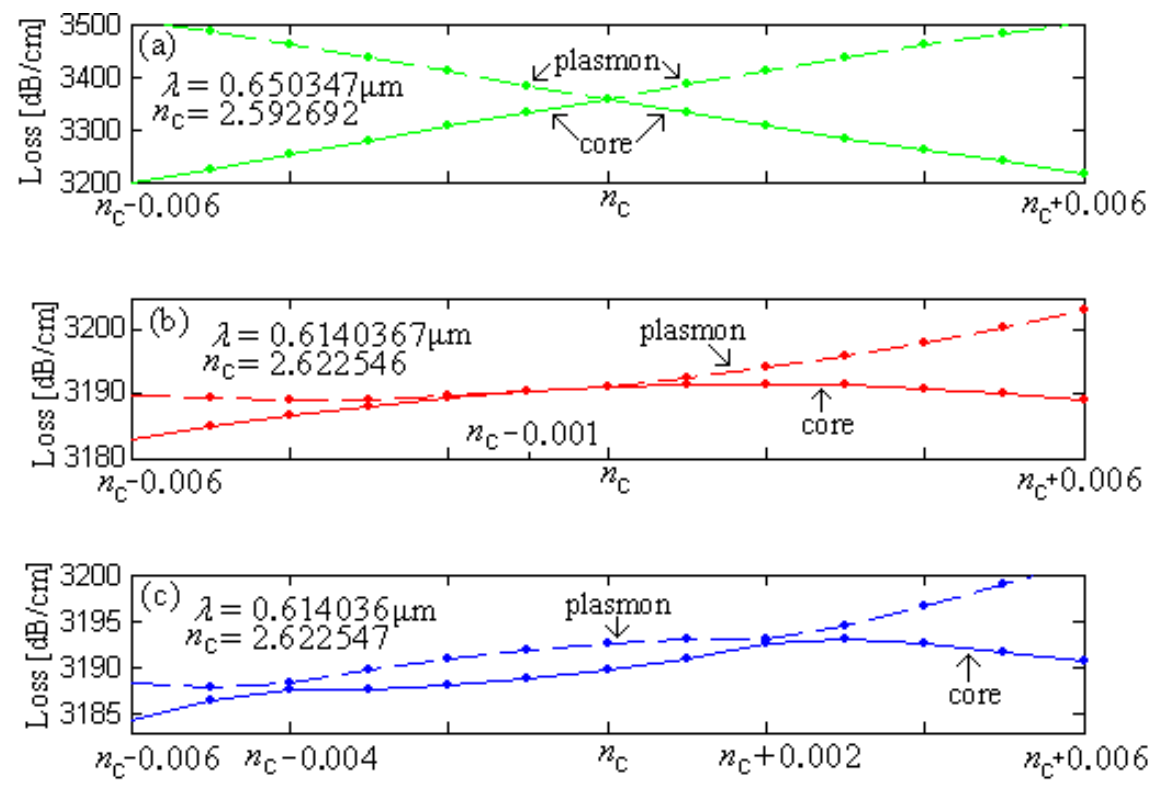

Figure 9. The loss versus variation of chalcogenide refractive index for the core and plasmon modes near the loss matching point $\left(\lambda=0.650347 \mu m\right.$ for $d_{2}=$ $70 \mathrm{~nm}(\mathrm{a}), \lambda=0.6140367 \mu \mathrm{m}$ for $d_{2}=40 \mathrm{~nm}$ (b) and $\lambda=0.614036 \mu \mathrm{m}$ for $\left.d_{2}=40 \mathrm{~nm}(\mathrm{c})\right)$.

The resonant wavelength is decreased with only $0.128 \mathrm{~nm}$ at $\lambda=0.613908 \mu \mathrm{m}$, when $n_{\mathrm{c}}$ is increased with 0.04 to take into account a photoinduced change of the refractive index obtained by illumination the chalcogenide $\mathrm{As}_{2} \mathrm{~S}_{3}$ layer with a 
laser beam $\left(\lambda=514.5 \mathrm{~nm}, I=10 \mathrm{mWmm}^{-2}\right)$. In this case, the loss $\alpha$ for the core mode is increased with $41 \mathrm{~dB} / \mathrm{cm}$ at $3230.7 \mathrm{~dB} / \mathrm{cm}$ and the effective index $\beta / k$ for the core and plasmon modes are $1.4511524471+0.0036342283 \mathrm{i}$ and $1.4506230194+0.0036343274 \mathrm{i}$, respectively.

\section{Conclusions}

The previous simulations highlights that the advantages of a four-layer Bragg fiber plasmonic biosensor for aqueous analytes with an $\mathrm{As}_{2} \mathrm{~S}_{3}$ layer (hence a structure with $\mathrm{SiO}_{2}$, $\mathrm{As}_{2} \mathrm{~S}_{3}$, gold and $\mathrm{H}_{2} \mathrm{O}$ layers) instead of a GaP layer with same thickness $\left(d_{2}=40 \mathrm{~nm}\right.$ as used in previously reported sensor) are: smaller value of the full width at half maximum (FWHM $=14.0 \mathrm{~nm}$ versus $19.4 \mathrm{~nm}$ ), larger value of the signal-tonoise ratio $(S N R=0.23$ versus 0.17$)$, higher loss ( $\alpha=$ $3189.7 \mathrm{~dB} / \mathrm{cm}$ versus $3091.0 \mathrm{~dB} / \mathrm{cm}$ ), but a smaller value of the maximum of amplitude sensitivity $\left(S_{\mathrm{A}}=397.9 \mathrm{RIU}^{-1}\right.$ versus 3708.8 $\mathrm{RIU}^{-1}$ ). However, if the thickness of the $\mathrm{As}_{2} \mathrm{~S}_{3}$ layer is increased to the value for which it is quarter wavelength $\left(d_{2}=70 \mathrm{~nm}\right)$, the power fraction carried at the resonant wavelength $(\lambda=0.650347 \mu \mathrm{m})$ by the core guided mode in the analyte and in $\mathrm{SiO}_{2}$ layers becomes comparable with the values obtained in an optical fiber with the previously reported $\mathrm{GaP}$ layer thickness, evidencing that the higher value of the refractive index for the GaP layer is compensated by a larger value of the thickness $d_{2}$ for the $\mathrm{As}_{2} \mathrm{~S}_{3}$ layer. The interest for substituting the $\mathrm{GaP}$ layer with an $\mathrm{As}_{2} \mathrm{~S}_{3}$ layer is in the possibility to change the refractive index of the latter by exposure to intense laser light. This photoinduced effect has been taken into account, obtaining that for an increase of the refractive index $n_{\mathrm{c}}$ of the $\mathrm{As}_{2} \mathrm{~S}_{3}$ layer by 0.04 , the resonant wavelength is decreased by $0.128 \mathrm{~nm}$ and the loss $\alpha$ for the core mode is increased by $41 \mathrm{~dB} / \mathrm{cm}$.

\section{References}

[1] M. Skorobogatiy, J. Sens. 524237, 1 (2009).

[2] B. Gauvreau, A. Hassani, M. Fassi Fehri, A. Kabashin, M. Skorobogatiy, Opt Express 15, 11413 (2007).

[3] V. A. Popescu, N. N. Puscas, G. Perrone, JOSA B 32, 473 (2015).

[4] V. A. Popescu, N. N. Puscas, G. Perrone, Mod. Phys. Lett. B 30, 1650075 (2016).

[5] V. A. Popescu, N. N. Puscas, Rom. Rep. Phys. 67, 500 (2015).

[6] V. A. Popescu, N. N. Puscas, G. Perrone, Plasmonics 11, 1183 (2016).

[7] V. A. Popescu, Plasmonics Application of a plasmonic biosensor for detection of human-liver tissues Plasmonics, Published online: 18 February 2017, doi:10.1007/s11468-0170546-9

[8] A. Zakery, J. Phys. D, Appl. Phys. 35, 2909 (2002).

[9] A. K. Sharma, R. Rajan, B. D. Gupta, Opt. Commun. 274, 320 (2007).

[10] R. K. Verma, A. K. Sharma, B. D. Gupta, Opt. Commun. 281, 1486 (2008).

[11] A. K. Ghatak, K. Thyagarajan, Introduction to Fiber Optics (Cambridge University Press, 1999).

[12] M. Daimon, A. Masumura, Appl. Opt. 46, 3811 (2007).

[13] W. S. Rodney, I. H. Malitson, T. A. King, J. Optical Soc. of America 48, 633 (1958).

[14] M. A. Ordal, L. L. Long, R. J. Bell, S. E. Bell, R. R. Bell, R. W. Alexander Jr, C. A. Ward, Appl. Opt. 22, 1099 (1983).

[15] A. Shalabney, I. Abdulhalim, Opt Lett. 37, 1175 (2012). 